\title{
Polymerizing Bone Cement can Roughen a Polyethylene Bearing Surface on Total Hip Replacement - A Surface Analysis
}

Paul YF Lee ${ }^{1^{*}}$, Phillip Alderman ${ }^{2}$ and Paul Roberts ${ }^{2}$

${ }^{1}$ Welshbone, South Wales Orthopaedics Research Network, Wales, UK

${ }^{2}$ Royal Gwent Hospital, Aneurin Bevan University Health Board, Newport, Wales, UK

*Corresponding author: Paul YF Lee, Welshbone, South Wales Orthopaedics Research Network, Wales, UK, Tel: +447764614688; E-mail: paul@welshbone.com

Rec date: May 17, 2016; Acc date: June 9, 2016; Pub date: June 15, 2016

Copyright: ( 2016 Lee PYF, et al. This is an open-access article distributed under the terms of the Creative Commons Attribution License, which permits unrestricted use, distribution, and reproduction in any medium, provided the original author and source are credited.

\section{Abstract}

The tribological behaviour of the bearing surface in hip arthroplasty is greatly influenced by its surface roughness. During cemented hip arthroplasty, bone cement may contaminate the bearing surface. Hence, the aim of this study was to investigate the effect of cement polymerization on a highly cross-linked polyethylene(HCLP) bearing surface as any process influences the surface roughness of the bearing surface can have potential long term effect on the wear rate.
\end{abstract}

Three new HCLP liners were used. A map of the surface topography of each liner was obtained using a white light interferometric microscope at five different locations in accordance with the standard BSEN ISO 4288:1998. Bone cement was then applied to the bearing surface and allowed to polymerise, then removed and irrigated with saline. The surface roughness measurement procedure was repeated again for all samples.

The $\mathrm{Ra}$ results showed a $21 \%$ increase in mean surface roughness after cement contamination $(p=0.01)$. The average Ra value pre-contamination was $190 \mathrm{~nm}$ while post-contamination was $230 \mathrm{~nm}$. There were also changes in the surface topography observed with 3D surface mapping.

Our study indicates that bone cement contamination of the HCLP surface can significantly increase its surface roughness and alter its surface topography. Surgeons should be aware of this potentially serious effect on the bearing and be vigilant to avoid bone cement contamination during arthroplasty surgery.

Keywords: Bone cement; Surface roughness; Polyethylene bearing surface; Tribology; Arthroplasty; Total hip replacement

\section{Introduction}

Since Sir John Charnley first used bone cement in conjunction with the Low Friction Arthroplasty in 1962, poly methyl methacrylate (PMMA) bone cement and polyethylene has been used extensively in total hip arthroplasty (THA) [1]. Cemented THA has been found to be durable and the cemented femoral component has proven to be the best performing implant in many cases [2-4]. However, wear of polyethylene and the associated periprosthetic osteolysis have been the dominant problems in total hip arthroplasty [5]. As material technology developed, increasing the cross-link density of the polyethylene has been shown to markedly decrease the wear rate [5-7]. Therefore the use of highly cross-linked polyethylene (HCLP) became popular in THA.

During cementation and pressurization of the femoral stem and/or acetabular component, it is possible that bone cement could extrude around the implants and contaminate the bearing surface of the acetabular liner/component. If not detected, the bone cement would polymerize on the surface of the polyethylene bearing surface. Polymerization of methyl methacrylate (MMA) to PMMA is an exothermic reaction, which generates considerable heat, $57 \mathrm{KJ}(13.8$ kcal) per mole of MMA [8]. There has been extensive research describing the thermal effect between the bone cement interface
[6,7,9-12], however its effect on the bearing surface has never been investigated. Furthermore, there have not been any reports investigating the chemical effect of bone cement polymerization on HCLP.

Polyethylene and HCLP is a heat sensitive material; its mechanical properties can potentially be altered by this thermal effect during cement polymerization [8]. The aim of this study was to investigate whether this exothermic process can affect the surface roughness of the HCLP bearing surface. This is particularly important as the tribological behavior of the bearing surface in hip arthroplasty can be greatly influenced by its surface finish [10].

\section{Method}

Three new, sterile packed highly cross-linked polyethylene (HCLP) liners (Longevity', Zimmer, Warsaw, USA) were used in this study. A map of the surface topography of each liner was obtained using a white light interferometric microscope - MicroXAM-100-HR (ADE Phase Shift, Tuscon, USA) at five fixed locations. These data were then used to extract roughness profiles in accordance with the standard BS EN ISO 4288:1998. In brief, this standard specifies the rules and procedures that should be followed when assessing surface texture metrics on parts, so that results can be comparable between those obtained in different laboratories. In this way, 3D surface mapping data was first extracted at the set locations for each liner. 
Citation: Lee PYF, Alderman P, Roberts P (2016) Polymerizing Bone Cement can Roughen a Polyethylene Bearing Surface on Total Hip

The arithmetical mean roughness $(\mathrm{Ra})$ of the surfaces could then be derived from these data. Sterile Palacos R-40 bone cement (Heraeus $\mathrm{GmbH}$, Wehrheim, Germany) was then mixed according to the manufacturer's guidance and applied manually to the bearing surface and allowed to polymerize. After 15 minutes, the bone cement was removed with a sterile theatre swab and the component was irrigated with $100 \mathrm{ml}$ of normal saline until it was visually clean. In total 30 points data were collected with the samples.

Following this, the surface roughness measurement procedure was repeated at the same fixed locations for all samples, which enabled $\mathrm{Ra}$ values prior and post treatment to be compared. In addition, JEOL 6480LV Scanning Electron Microscopy and Energy-dispersive X-ray (EDX) spectroscopy Oxford Instruments Inca X-ray analysis system (Oxford Instruments, Abingdon, United Kingdom) were used to inspect the bearing surface for elements analysis pre and post cementation.

All statistical analyses were performed using the Statistical Package for Social Scientists (SPSS, version 20, USA). Values of Ra were analyzed using one-way ANOVA tests with repeated measures. Prior to running all ANOVA tests, data was checked for sphericity using Mauchly's test.

Where sphericity violations were noted Huyn-Feldt corrections were used to modify the degrees of freedom employed in the subsequent statistical analyses. Statistical significance was accepted at $p$ $\leq 0.05$ and, where statistical significance was noted, post-hoc (Bonferroni) pair-wise comparisons were made to determine specifically where differences existed.

\section{Results}

The mean surface roughness value of the HCLP prior to cementation was $190 \mathrm{~nm}$ (S.D. 52), while post-contamination it was $230 \mathrm{~nm}$ (S.D. 54). Thus, there was a $21 \%$ increase in the mean surface roughness after cement contamination, which was found to be statistically significant $(p=0.01)$. Changes in the surface topography could also be observed with the $3 \mathrm{D}$ surface mapping data as illustrated in Figures 1 and 2.

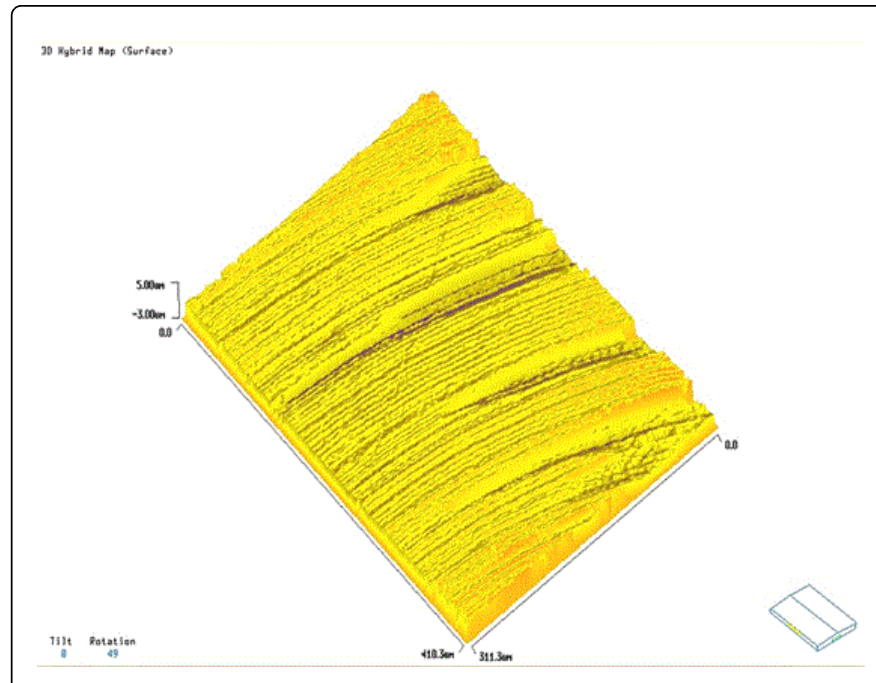

Figure 1: Surface topography of 3D surface mapping of the HCLP according to BS EN ISO 4288:1998 before bone cement contamination.

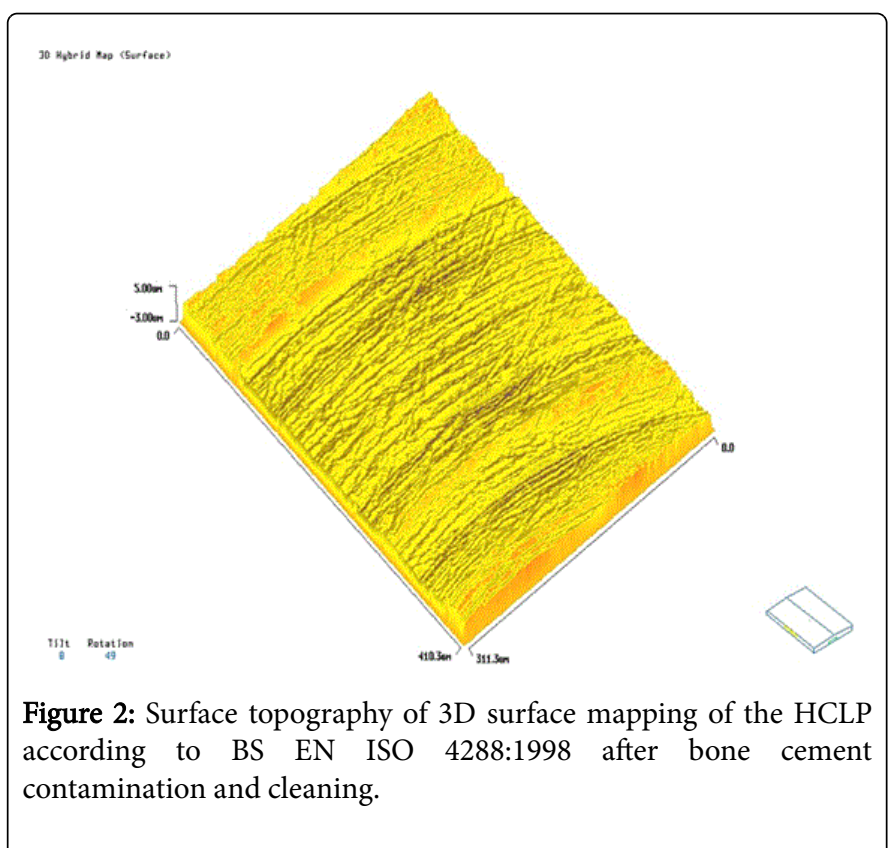

Prior to PMMA contamination (Figure 1), 3D surface mapping clearly demonstrated uniform and regular groves on the HCLP produced by the machining process. After PMMA contamination (Figure 2), the groves on the HCLP have become irregular with multiple pits. This effect has become more evident with the SEM analysis as illustrated in Figures 3 and 4.

There were multiple irregular pits on the HCLP surface around the machine marks post PMMA contamination (Figure 4). Further EDX inspection did not reveal any bone cement particle residue on the HCLP surface. 


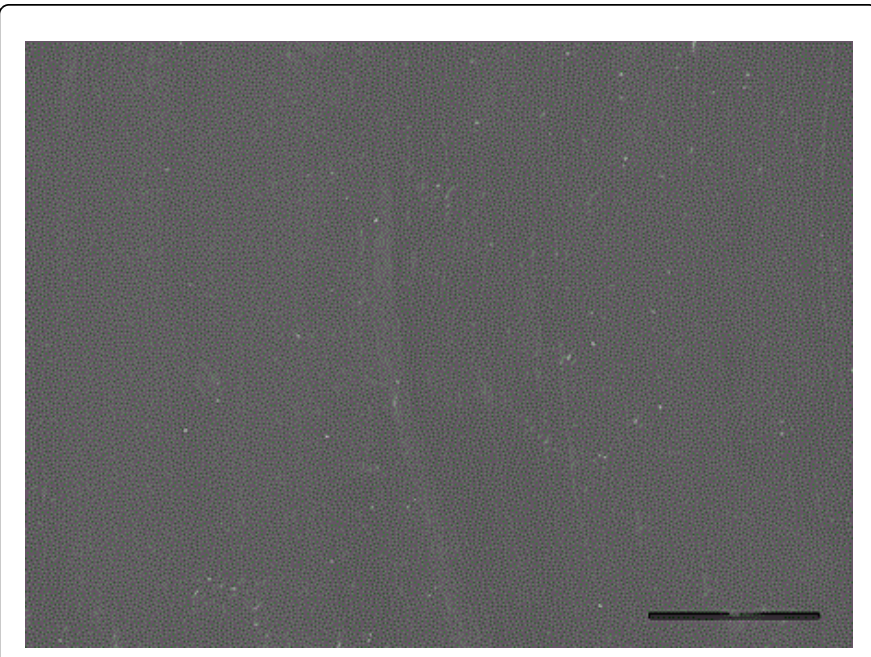

Figure 3: Scan election microscopy (SEM) photograph of the HCLP prior to cement contamination. Regular machine marks can be seen on the surface.

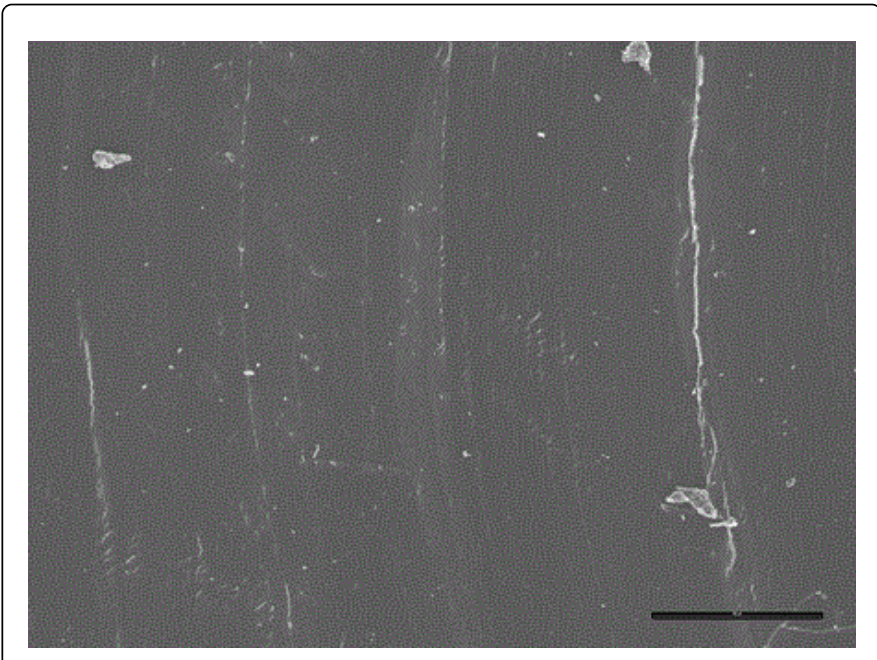

Figure 4: Scan election microscopy (SEM) photograph of the HCLP after cement contamination. Irregular pattern can be seen around the machine mark due to thermal damage to the surface.

\section{Discussion}

The results from this study suggest that bone cement polymerization on the HCLP surface could significantly increase the surface roughness of the HCLP. This effect is likely induced by the heat energy released by the PMMA during the polymerization process. Polyethylene is a thermoplastic material, which was radiated to cross-link in order to produce HCLP; it was then re-melted or annealed to reduce the free radicals and crystallinity $[13,14]$. A range of temperature between 110 to $150^{\circ} \mathrm{C}$ have been used by different manufacturers to facilitate this process [13]. Therefore polyethylene and HCLP are heat sensitive; the changes on surface roughness demonstrated in this study are likely caused by heat generated during PMMA polymerization.
When the liquid monomer components of PMMA are mixed with methylmethacrylate, it polymerizes with heat generation of 2,600 calories per one commercial unit [11]. This heat is generated rapidly and the rise of temperature will depend on the environment surrounding the PMMA and the thermal characteristics and surface area of the interface, with the peak temperature ranging from 80 to $124^{\circ} \mathrm{C}[11,15]$. Many reports suggest that the bone-cement interface would only reach a peak temperature of $41-60 \mathrm{C}^{\circ}$ due to the surface area and circulating blood $[11,15,16]$. However on the articular side of the HCLP the situation would be different, as HCLP is a good heat insulator and there is no circulating blood or trabecular bone network to dissipate the heat. The heat energy generated by PMMA polymerization is proportional to its quantity and differs between manufactures. Theatre temperature, humidity, mixing technique and handling of PMMA can affect the polymerization process, hence the rate of the heat energy generated. It is important for the surgeon to also consider the thickness of the HCLP liner/cup and its insulation effect when dealing with PMMA contamination. Although from our EDX analysis, it is suggested that $100 \mathrm{ml}$ of saline wash is sufficient to remove any contaminant particles, the HCLP would have been damaged by the heat energy from polymerization of bone cement.

\section{Wear}

According to the Archard model for sliding wear, as seen below, wear is associated with interactions between plastically deforming asperities on the sliding surfaces, and leads to the equation [17].

\section{$\mathrm{Q}=(\mathrm{KW}) / \mathrm{H}$}

$\mathrm{Q}$ is the volume of material removed from the surface by wear per unit sliding distance, $\mathrm{K}$ is Archard wear coefficient, $\mathrm{W}$ is the normal load applied between the surfaces, and $\mathrm{H}$ is the indentation hardness of the softer surface [17].

Many sliding systems do show a relatively linear dependence of wear on sliding distance, and under some conditions also show wear rates which are roughly proportional to normal load [17]. Therefore the value of $\mathrm{K}$ is of fundamental importance, and provides a valuable means of comparing the severity of different wear processes [17]. Although in many cases of sliding wear, $\mathrm{K}$ is effectively constant over quite large ranges of load or sliding speed, in some instances sharp transitions can occur, and $\mathrm{K}$ may change by a factor of 100 or even 1000 for a relatively small change in the conditions [17]. This behavior is associated with a change in the predominant mechanism of material removal; for this reason a small change in the Ra of the bearing surface would alter the instance of sharp transition between surface which would affect the Archard wear coefficient $(\mathrm{K})$ which may alter the wear rate by a factor of 1000 [17].

Retrieval study demonstrated the polishing effects of the conventional polyethylene during the initial phase of wear and further reduced the $\mathrm{Ra}$ [18]. However, such effects were not seen in the highly cross-linked polyethylene, where scratches and folds were reported to accumulate at the contact area [18]. Therefore the change of the surface roughness of the polyethylene will have a higher significant influence to the tribological behavior in the highly cross-linked polyethylene group.

\section{Lubrication}

Boundary or severe mixed conditions can be used to describe the lubrication characteristics of the polyethylene on metal bearing surface 
of a hip joint $[19,20]$. It is unlikely for this type of bearing surface to achieve fluid film lubrication. However, the increase in surface roughness $(\mathrm{Ra})$ would have an effect on in the lubrication as described by the equation below, and further reduce $\lambda$ which reduces the chance of hydrodynamic and elastohydrodynamic lubrication [17].

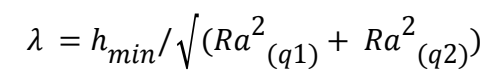

$\lambda$ is a measure of the extent of asperity interactions during lubricated sliding. hmin is minimum film thickness in a lubricated contact. is the surface roughness of the combined bearing surface [17].

Surface roughness and its orientation has been proven to have a significant effect on elastohydrodynamic lubrication, especially when the $\lambda$ ratio is in the range between 0.05 to $1.0[21,22]$. High friction and wear occur unless surfaces are protected by a boundary lubricant. The boundary lubricants act by forming chemisorbed films on the opposing surfaces, which prevent or limit direct contact between the

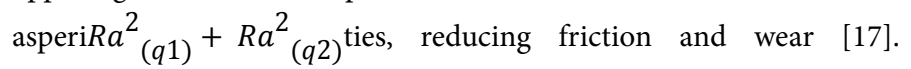
Increased Ra will lead to higher asperities between the surfaces and in theory more boundary lubricants would be required to achieve the same lubrication effect.

\section{Friction}

Friction is a resisting force encountered by one body moving over another, high friction associated with high wear $[17,23]$. Friction force is directly proportional to the force applied and the coefficient of fraction. Assuming the surgical conditions and implant have not changed for a given bearing surface, changes in surface roughness (Ra) will affect the coefficient of friction, which will have a direct impact on the fictional force $[17,23]$. The level of interface roughness at which the transition from interfacial to cohesive wear occurs depends on the nature of the polymer, but corresponds typically to Ra (arithmetic mean roughness) values between $0.01 \mu \mathrm{m}$ and $1 \mu \mathrm{m}$ [17].

Therefore an increase in surface roughness ( $\mathrm{Ra}$ ) of the polyethylenebearing surface after cement contamination on the bearing surface would affect wear, lubrication and friction of the bearing surface, which may have adverse effects on the longevity of the implant.

\section{Conclusion}

Bone cement contamination and subsequent polymerization on the surface of highly cross-linked polyethylene can significantly increase its surface roughness and alter its surface topography. These changes are likely to affect the tribology of the bearing surface and even its long-term performance. Surgeons should be aware of this potentially serious effect on the bearing and be vigilant to avoid bone cement contamination during arthroplasty surgery.

\section{References}

1. Charnley J (1972) The long-term results of low-friction arthroplasty of the hip performed as a primary intervention. J Bone Joint Surg Br 54: 61-76.

2. Gillam MH, Ryan P, Graves SE, Miller LN, de Steiger RN, et al. (2010) Competing risks survival analysis applied to data from the Australian Orthopaedic Association National Joint Replacement Registry. Acta Orthop 81: 548-555.
3. Mäkelä K, Eskelinen A, Pulkkinen P, Paavolainen P, Remes V (2008) Cemented total hip replacement for primary osteoarthritis in patients aged 55 years or older: results of the 12 most common cemented implants followed for 25 years in the Finnish Arthroplasty Register. J Bone Joint Surg Br 90: 1562-1569.

4. Mäkelä KT, Eskelinen A, Pulkkinen P, Paavolainen P, Remes V (2008) Total hip arthroplasty for primary osteoarthritis in patients fifty-five years of age or older. An analysis of the Finnish arthroplasty registry. J Bone Joint Surg Am 90: 2160-2170.

5. Bragdon CR, Jasty M, Muratoglu OK, Harris WH (2005) Third-Body Wear Testing of a Highly Cross-Linked Acetabular Liner: The Effect of Large Femoral Head Size in the Presence of Particulate Poly(MethylMethacrylate) Debris. J Arthroplasty 20: 379-385.

6. Muratoglu OK (2001) The comparison of the wear behavior of four different types of crosslinked acetabular components. J Orthop Res 19: 1210 .

7. Muratoglu OK, Bragdon CR, O'Connor DO, Jasty M, Harris WH (2001) A novel method of cross-linking ultra-high-molecular-weight polyethylene to improve wear, reduce oxidation, and retain mechanical properties. Recipient of the 1999 HAP Paul Award. J Arthroplasty 16: 149-160.

8. Breusch S, Malchau H (2005) The Well-Cemented Total Hip Arthroplasty - Theory and Practice. Springer, USA.

9. Ito H, Maloney CM, Crowninshield RD, Clohisy JC, McDonald DJ, et al. (2010) In vivo femoral head damage and its effect on polyethylene wear. J Arthroplasty 25: 302-308.

10. Kim YH, Ritchie A, Hardaker C (2005) Surface roughness of ceramic femoral heads after in vivo transfer of metal: correlation to polyethylene wear. J Bone Joint Surg Am 87: 577-582.

11. Saha S, Pal S (1984) Mechanical properties of bone cement: a review. J Biomed Mater Res 18: 435-462.

12. Toksvig-Larsen S, Franzen H, Ryd L (1991) Cement interface temperature in hip arthroplasty. Acta Orthop Scand 62: 102-105.

13. Kurtz SM, Manley M, Wang A, Taylor S, Dumbleton J (2002) Comparison of the properties of annealed crosslinked (Crossfire) and conventional polyethylene as hip bearing materials. Bull Hosp Jt Dis 61: 17-26.

14. Kurtz SM, Turner JL, Herr M, Edidin AA (2002) Deconvolution of surface topology for quantification of initial wear in highly cross-linked acetabular components for THA. J Biomed Mater Res 63: 492-500.

15. Wykman AG (1992) Acetabular cement temperature in arthroplasty. Effect of water cooling in 19 cases. Acta Orthop Scand 63: 543-544.

16. Shields SL, Schulz KS, Hagan CE, Kass P (2002) The effects of acetabular cup temperature and duration of cement pressurization on cement porosity in a canine total hip replacement model. Vet Surg 31:167-173.

17. Hutchings I (2001) Encyclopedia of Materials - Science and Technology. Buschow KHJ, Cahn RW, Flemings MC, Ilschner B, Kramer EJ, Mahajan S, editors. Elsevier Science Ltd, UK.

18. Rieker CB, Konrad R, Schön R, Schneider W, Abt NA (2003) In vivo and in vitro surface changes in a highly cross-linked polyethylene. J Arthroplasty 18: 48-54.

19. Scholes SC, Unsworth A (2000) Comparison of friction and lubrication of different hip prostheses. Proc Inst Mech Eng H 214: 49-57.

20. Scholes SC, Unsworth A (2006) The effects of proteins on the friction and lubrication of artificial joints. Proc Inst Mech Eng H 220: 687-693.

21. Zhu D, Jane Wang Q (2013) Effect of Roughness Orientation on the Elastohydrodynamic Lubrication Film Thickness. Journal of Tribology 135: 031501.

22. Zhu D, Wang QJ (2012) On the $\lambda$ ratio range of mixed lubrication. Journal of Engineering Tribology 226: 1010-1022.

23. Dowson D (2001) New joints for the Millennium: wear control in total replacement hip joints. Proc Inst Mech Eng H 215: 335-358. 